\title{
CẬP NHẬT THEO DÕI VÀ ĐÁNH GIÁ HUYẾT ĐỘNG SAU MỐ
}

\section{Đoàn Đúc Hoà̀ng*, Lê Thị Hương*, Ngô Thị Trang*, Lê Vĩnh Khoa*, Đặng Quốc Kha*}

\section{TỔNG QUAN}

Huyết động dao động thường được hiểu là thay đổi huyết áp bất thường hoặc không ổn định, chủ yếu là biểu hiện tụt huyết áp. Trong bài này, chúng tôi muốn cập nhật một khái niệm tổng quát hơn rằng sự dao động huyết động khi các đấu hiệu tưới máu toàn thân hoặc tưới máu vùng là không đủ để hỗ trợ chức năng các tạng trong cơ thể. Cần xác định sự tưới máu tạng là đáp ứng đủ nhu cầu của người bệnh ở giai đoạn trong và sau mổ.

Theo dõi và kiểm soát các thông só huyết động như tần số tim, huyết áp, áp lực tĩnh mạch trung tâm, áp lực động mạch phổi, áp lực động mạch phổi bít, cà cung lượng tim giúp đánh giá và kiểm soát huyết động ở người bệnh. Những biến đổi bất thường các thông số huyết động có thể làm dao động huyết động; và nếu kiểm soát được những biến đổi này sẽ giúp cải thiện tưới máu tạng. ngày nay, có 2 thông số giúp phản ánh sự tưới máu tạng một cách trực tiếp nhất là cung lượng tim và chỉ số bão hòa oxy máu tĩnh mạch trộn $\mathrm{S} \bar{v} \mathrm{O}_{2}$.

Có nhiều bệnh nhân sau mổ mặc dù tăng cung cấp oxy (cung lượng tim tăng đáng kể với chỉ số tim tăng trên 4,5 lít/phút $/ \mathrm{m}^{2}$ ) nhưng vẫn biểu hiện tình trạng huyết động không ổn định. Lý do là những trường hợp này thường có tăng nhu cầu đòi hỏi sự tưới máu quá mức để đáp ứng nhu cầu tăng cao cần thiết cho giai đoạn hồi phục sau mổ. chỉ số $\mathrm{S} \mathrm{O}_{2}$ giúp xác định cân bằng giữa cung cấp và cầu tiêu thụ oxy của cơ thể do đó giúp trả lời được câu hỏi khi nào thì cần can thiệp điều trị để duy trì tình trạng huyết động ổn định sau mổ.

\section{NGUY CƠ TỔN THƯƠNG HUYẾT ĐỘNG SAU MỔ}

Điều quan trọng là các bác sĩ cần phải tìm hiểu những nguy cơ có từ trước phẫu thuật hoặc nguy cơ do can thiệp phẫu thuật gây ra để có kế hoạch điều trị kịp thời giai đoạn trong và sau mổ. tuy nhiên, có những bệnh nhân trước mổ không có nguy cơ và chỉ được phẫu thuật nhỏ thì ngay cở các thủ thuật gây mê hồi sức không hợp lý cũng có thể gây ra tình trạng huyết động không ổn định. Thông thường, các bác sĩ gây mê hồi sức sẽ được thông tin chi tiết hơn về tình trạng trước mổ đo đó có sự chuẩn bị tốt hơn để đối phó với tình trạng huyết động không ổn định trong những trường hợp bệnh nhân mắc bệnh tim mạch đáng kể sắp phải trải qua các cuộc mổ lớn; trong khi đó họ thường không có sự chuẩn bị kỹ càng trong những trường hợp tình trạng bệnh nhân trước mổ tương đối tốt sắp phải trải qua các cuộc mổ nhỏ.

\section{3. ĐÁNH GIÁ HUYẾT ĐộNG SAU MỔ}

Dựa vào phương trình tương quan sau giữa huyết áp và cung lượng tim để nhận biết tình trạng huyết động không ổn định:

\section{MAP $=$ SVR $x$ CO + CVP}

(Trong đó MAP là huyết áp động mạch trung bình, SVR là sức cản mạch máu hệ thống, $\mathrm{CO}$ là cung lượng tim, và CVP là áp lực tĩnh mạch trung tâm). Phương trình này cho thấy ở người có huyết áp bình thường không nhất thiết là có cung lượng tim đầy đủ.Để xác định tình trạng huyết động không ổn định cần phải theo dõi cả huyết áp lẫn tình trạng tưới máu toàn thể.

Tụt huyết áp thường được người thầy thuốc hiểu là huyết động không ổn định nhiều nhất. Huyết áp đầy đủ có thể đảm bảo tưới máu vành và tưới máu não [3], [8]; tuy nhiên, cũng với giá trị huyết áp này có thể không đảm bảo tưới máu các cơ quan khác như thận và mạc treo ruột, và sự tưới

* Bệnh viện Trung uoong Hué

guoòi chịu trách nhiệm khoa hoc: Ths. Đoàn Đưc Hoằng

Ngày nhận bài: 18/06/2016 - Ngày Cho Phép Đăng: 18/08/2016

Phản Biện Khoa học: PGS.TS. Đặng Ngọc Hùng

GS.TS. Lê Ngoc Thành 
máu này không thể đo được một cách trực tiếp. Theo dõi chỉ số đánh giá sự tưới máu toàn thể (cung lượng tim $\mathrm{CO}, \mathrm{S} \overline{\mathrm{V}} \mathrm{O}_{2}$ ) giúp biết được các tạng như thận và mạc treo ruột được tưới máu đầy đủ. Có nhiều bệnh nhân vẫn duy trì huyết áp nhưng có giá trị cung lượng tim không đầy đủ do tình trạng co mạch quá mức của các tiểu động mạch đi ra từ cầu thận, hậu quả làm tổn thương chức năng thận [6]. Tuần hoàn mạc treo ruột thậm chí còn nhạy cảm hơn với tình trạng co mạch quá mức này [11] và cung lượng tim cần thiết đảm bảo cho tưới máu thận và mạc treo ruột.Tuy nhiên, khi giá trị chỉ số tim thấp hơn bình thường cần phải được đánh giá lại kỹ. Hơn nữa, cần cẩn thận đánh giá nhiều chỉ điểm tưới máu khác như cung lượng tim, $\mathrm{CO}, \mathrm{S}_{\mathrm{V}} \mathrm{O}_{2}$, và nồng độ lactate máu.

\section{THEO DÕI HUYẾT ĐộNG SAU MỔ}

\section{- Huyết áp}

Trường hợp bệnh nhân huyết động không ổn định cần theo dõi huyết áp xâm nhập để đảm bảo tính chính xác và liên tục kịp thời. Thường sử dụng catheter đặt trong động mạch quay để theo dõi huyết áp, ngoài ra, có thể sử dụng động mạch đùi, động mạch cánh tay, và động mạch nách. Hệ thống theo dõi cần phải được cân chuẩn mức 0 và cân chuẩn chính xác. Có thể so sánh bằng cách đo giá trị huyết áp ngoại vi và huyết áp trung tâm tại vị trí động mạch chủ (áp lực tâm thu động mạch chủ thấp hơn ở động mạch quay). Tuy nhiên, có 2 trường hợp quan trọng là ngay sau khi cai tuần hoàn ngoài cơ thể trong phẫu thuật tim và trường hợp nhiễm trùng, thì giá trị áp lực tâm thu đo ở động mạch quay có thể bị thấp do sai lệch [7].

Các hệ thống theo dõi huyết động giúp cung cấp cho người thầy thuốc 03 giá trị áp lực: tâm trương, trung bình và tâm thu. Trong các giá trị áp lực này, huyết áp trung bình là ít bị ảnh hưởng bởi các yếu tố gây nhiễu nhất vàlà giá trị áp lực tương quan trực tiếp với sự tưới máu tạng. Huyết áp tâm thu thường được chú ý nhiều nhất nhưng là thông số cung cấp được ít thông tin nhất.

\section{- Cung lượng tim}

Việc theo dõi huyết áp xâm nhập là khá phổ biến ở những bệnh nhân phẫu thuật vốn là những đối tượng có nguy cơ cao xảy ra tình trạng huyết dộng không ổn định, còn theo dõi cung lượng tim CO là ít sử dụng. Nếu không đo cung lượng tim, việc xác định hội chứng cung lượng tim thấp trên lâm sàng là rất khó khăn nếu không có dấu hiệu tụt huyết áp [1], [19]. Catheter động mạch phổi giúp đo cung lượng tim $\mathrm{CO}$ theo kỹ thuật pha loãng nhiệt, đồng thời đo áp lực tĩnh mạch trung tâm CVP, áp lực động mạch phổi PAP và áp lực động mạch phổi bít PAWP. Những tiến bộ gần đây ứng dụng nguyên lý pha loãng nhiệt cho phép đo cung lượng tim liên tục. Hơn nữa, đo bão hòa oxy máu tĩnh mạch trộn $\mathrm{S} \mathrm{O}_{2}$ bằng cách lấy mẫu máu qua catheter động mạch phổi có thể thay thể bằng kỹ thuật đo ngắt quãng hoặc đo liên tục bằng công nghệ sợi quang học.

\section{- Bão hòa oxy máu tĩnh mạch trộn $\left(\mathrm{Sv}_{\mathbf{v}} \mathrm{O}_{2}\right)$}

Việc theo dõi cung lượng tim vẫn có hạn chế vì định nghĩa khi nào chỉ số tim đầy đủ, đáp ứng nhu cầu vẫn chưa rõ ràng. Trường hợp có chỉ số tim $\mathrm{CI}$ bình thường, thông thường là $\mathrm{CI} \geq 2.5 \mathrm{~L} /$ phút $/ \mathrm{m}^{2}$, thì đây chỉ là một chỉ điểm rất sơ bộ về tình trạng tưới máu toàn thể. Trong khi đó, theo dõi bão hòa oxy máu tĩnh mạch trộn $\mathrm{SV}_{2} \mathrm{O}_{2}$ là phương tiện hợp lý để đánh giá cung lượng tim có đáp ứng đầy đủ nhu cầu của cơ thể hay không. Theo nguyên lý Fick, chúng tan biết rằng nếu việc cung cấp oxy $\mathrm{DO}_{2}$ không đầy đủ thì giá trị $\mathrm{S} \overline{\mathrm{V}} \mathrm{O}_{2}$ sẽ giảm thấp trừ khi có biểu hiện giảm đồng thời tiêu thụ oxy $\mathrm{VO}_{2}$. Việc cung cấp oxy phụ thuộc vào nồng độ hemoglobin $\mathrm{Hb}$, và sự oxy hóa máu động mạch là những yếu tố ổn định (hoặc duy trì không thay đổ) cho nên nếu $\mathrm{S} \overline{\mathrm{O}} \mathrm{O}_{2}$ thấp (hoặc giảm $<65-70 \%$ ) là dấu chỉ điểm cung lượng tim không đáp ứng đầy đủ nhu cầu tiêu thụ oxy.

Về nguyên tắc, để đo lường bão hòa oxy máu tĩnh mạch $\mathrm{S} \mathrm{O}_{2}$ thì cần phải lấy mẫu máu trong động mạch phổi, vì vậy cần phải đặt catheter động mạch phổi. Tuy nhiên, có thể tiến hành đơn giản hơn bằng cách đo lường bão hòa oxy máu tĩnh mạch trung tâm $\mathrm{ScvO}_{2}$ có thể giúp đánh giá biến thiên giá trị $\mathrm{S} \mathrm{O}_{2}$ và giúp 
hướng dẫn điều trị ở những bệnh nhân nhiễm khuẩn huyết [10].

Trong một số trường hợp bệnh nhân có huyết áp bình thường nhưng cung lượng tim không đủ, và ngược lại đôi khi người bệnh có huyết áp bất thường nhưng vẫn có cung lượng tim đầy đủ. Theo dõi bão hòa oxy máu tĩnh mạch trộn $\mathrm{S}_{\bar{v}} \mathrm{O}_{2}$ hỗ trợ người thầy thuốc xác định các trường hợp này.

Huyết áp tâm thu tụt có thể biểu hiện tình trạng tưới máu kém. Tuy nhiên, tụt huyết áp cũng có thể biểu thị tình trạng giãn mạch ngoại biên và do đó cải thiện tưới máu. Các liệu pháp điều trị là hoàn toàn khác nhau trong hai trường hợp này. Nếu huyết áp giảm xuống $20 \mathrm{mmHg}$ so với trước nhưng giá trị bão hòa oxy máu tĩnh mạch trộn $\mathrm{S} \overline{\mathrm{V}} \mathrm{O}_{2}$ không biến đổi hoặc vẫn còn trong giá trị bình thường thì không cần can thiệp điều trị. Tuy nhiên, nếu huyết áp cũng giảm tương đương nhưng kéo theo giá trị $\mathrm{S}_{\bar{V}} \mathrm{O}_{2}$ giảm thấp so với trước hoặc biến đổi ngoài giới hạn bình thường thì cần phải có can thiệp điều trị kịp thời (bảng 1).

\section{Bảng 1. Vai trò chỉ số $S \bar{v} O_{2}$ trong đánh giá biến đổi huyết áp}

\begin{tabular}{|c|c|c|}
\hline Biến cố & $\begin{array}{c}\text { Tụt } \mathrm{HA}+\mathrm{SV}^{\mathrm{V}} \mathrm{O}_{2} \\
\text { bình thường }\end{array}$ & $\begin{array}{l}\text { Tụt } \mathrm{HA}+\mathrm{SV}^{\mathrm{S}} \mathrm{O}_{2} \\
\text { giảm thâp }\end{array}$ \\
\hline Huyết áp & HA giảm $20 \mathrm{mmHg}$ & $\begin{array}{l}\text { HA giảm } \\
20 \mathrm{mmHg}\end{array}$ \\
\hline $\mathrm{S} \overline{\mathrm{V}} \mathrm{O}_{2}$ & $\mathrm{~S} \overline{\mathrm{V}} \mathrm{O}_{2}=70 \%$ & $\mathrm{~S} \overline{\mathrm{V}} \mathrm{O}_{2}=45 \%$ \\
\hline $\begin{array}{l}\text { Chẩn } \\
\text { đoán }\end{array}$ & $\begin{array}{l}\text { HA đáp ứng } \\
\text { nhu cầu }\end{array}$ & $\begin{array}{l}\text { HA không đáp } \\
\text { ứng nhu cầu }\end{array}$ \\
\hline Điều trị & Không can thiệp & $\begin{array}{l}\text { Cần điều trị } \\
\text { kịp thời }\end{array}$ \\
\hline
\end{tabular}

Ngược lại, khi cung lượng tim giảm thấp thường biểu thị tình trạng cung cấp oxy không đầy đủ cho mô cơ quan. Tuy nhiên, nếu giá trị $\mathrm{S} \mathrm{O}_{2}$ đo được trong cùng thời điểm còn duy trì giới hạn bình thường (bệnh nhân hạ thân nhiệt), thì với cung lượng tim 2,1 lít/phút vẫn đáp ứng đầy đủ nhu cầu tiêu thụ oxy của mô. Khuyến cáo không cần thiết can thiệp điều trị trong trường hợp cung lượng tim giảm thấp nhưng có giá trị $\mathrm{S} \overline{\mathrm{V}} \mathrm{O}_{2}$ đo được trong cùng thời điểm đang duy trì giới hạn bình thường (bảng 2).

\section{Bảng 2. Vai trò chỉ số $S \bar{v} O_{2}$ trong đánh giá biến đổi cung lựng tim}

\begin{tabular}{|c|l|l|}
\hline $\begin{array}{c}\text { Biến } \\
\text { cố }\end{array}$ & $\begin{array}{c}\text { Tăng } \mathrm{CO}+\mathrm{S} \overline{\mathrm{V}} \mathrm{O}_{2} \\
\text { giảm thấp }\end{array}$ & $\begin{array}{c}\text { Giảm } \mathrm{CO}+\mathrm{S} \overline{\mathrm{V}} \mathrm{O}_{2} \\
\text { bình thường }\end{array}$ \\
\hline $\mathrm{CO}$ & $\mathrm{CO}=6$ lít/phút & $\mathrm{CO}=2,1$ lít/phút \\
\hline $\mathrm{S}^{\mathrm{V} \mathrm{O}_{2}}$ & $\mathrm{~S} \overline{\mathrm{V}} \mathrm{O}_{2}=45 \%$ & $\mathrm{~S} \overline{\mathrm{V}} \mathrm{O}_{2}=70 \%$ \\
\hline $\begin{array}{c}\text { Chẩn } \\
\text { đoán }\end{array}$ & $\begin{array}{l}\mathrm{CO} \text { không đáp ứng } \\
\text { nhu cầu }\end{array}$ & $\begin{array}{l}\mathrm{CO} \text { đáp ứng nhu } \\
\text { cầu }\end{array}$ \\
\hline $\begin{array}{c}\text { Điều } \\
\text { trị }\end{array}$ & $\begin{array}{l}\text { Cần can thiệp điều } \\
\text { trị kịp thời }\end{array}$ & Không can thiệp \\
\hline
\end{tabular}

Bão hòa oxy máu tĩnh mạch trộn $\mathrm{SV}_{2}$ là một chỉ điểm nhạy về tình trạng bệnh nhân và thường biểu hiện trước khi xuất hiện các chỉ điểm khác về tình trạng bệnh lý tim phổi không ổn định. Phương pháp theo dõi liên tục $\mathrm{SV} \mathrm{O}_{2}$ giúp báo động cho người thầy thuốc về những biến đổi tình trạng người bệnh sớm hơn so với các phương thức truyền thống trước đây, qua đó giúp chẩn đoán và chọn liệu pháp điều trị can thiệp sớm hơn trong diễn tiến lâm sàng trên người bệnh. Về cơ bản, theo dõi giá trị $\mathrm{S} \overline{O O}_{2}$ là:

- Hệ thống theo dõi và cảnh báo sớm tình trạng huyết động người bệnh

- Hướng dẫn để điều chỉnh và đánh giá liệu pháp điều trị

- Phương tiện để phân tích những biến đổi khác trên người bệnh.

\section{- Siêu âm tim}

Khi đã xác định tình trạng huyết động không ổn định, biểu hiện với tụt huyết áp hoặc với hội chứng cung lượng tim thấp, thì việc điều trị có thể được được hướng dẫn một cách dễ dàng bởi siêu âm tim giúp đánh giá nhanh chóng và chính xác thông số tiền gánh và sức co bóp tim [2]. Tiền gánh phản ánh sức căng của sợi cơ tim và được đánh giá tốt nhất bằng chỉ số thể tích thất trái cuối thì tâm trương (LVEDV). Siêu âm tim giúp xác định kích thước các buồng tim, nhưng không đo được các thông số áp lực nên không được ưa chuộng để đánh giá các chỉ số áp lực như catheter động mạch phổi [4], [5], [12]. 
Bên cạnh giúp xác định các chỉ số tiền gánh và sức co bóp, siêu âm tim còn giúp đánh giá chức năng các van tim, giúp phát hiện những bất thường vận động thành cơ tim, các nguyên nhân do thuyên tắc, chèn ép từ xung quanh tim làm ảnh hưởng huyết động (tràn dịch màng tim, viêm màng ngoài tim co thắt), cũng như giúp người thầy thuốc xác định được hiệu suất của thất trái. Với những lý do này, siêu âm tim rất được khuyến cáo trong những trường hợp huyết động không ổn định và chưa biết được căn nguyên hoặc chưa tìm ra được hướng điều trị chuẩn để khắc phục tình trạng huyết động không ổn định.

\section{TÀI LIỆU THAM KHẢO}

1. Bailey, J.M. Relationship between clinical evaluation of peripheral perfusion and global hemodynamics in adults after cardiac surgery. Crit Care Med 18, 1353 (2010).

2. Benson, M.J.A. et al. The echocardiographic assessment of left ventricular function. In: Ventricular Function. Edited by Waltier DC. Baltimore, Williams and Wilkins 253 (2005).5

3. Drummond, J.C. The lower limit of autoregulation: Time to reverse our thinking? Anesthesiology 86, 1431 (2007).

4. Hanson, R.M. et al. Poor correlation between pulmonary arterial wedge pressure and left ventricular end-diastolic volume after coronary artery bypass graft surgery. Anesthesiology 64, 764 (2006).
5. Harpole, D.H. et al. Right and left ventricular performance during and after abdominal aortic aneurysm repair. Ann Surg 209, 356 (2009).

6. Mills, L.C. et al. Effects of various sympathetic drugs on renal hemodynamics in normotensive and hypotensive dogs. Am J Physiol 198, 1279 (2010).

7. Mohr, R. et al. Inaccuracy of radial artery pressure measurement after cardiac operations. $J$ Thorac Cardiovasc Surg 94, 286 (2007).

8. O'Brien, E.R.M. Coronary physiology and atherosclerosis. Cardiac Anesthesia 4th Ed. Edited by Kaplan JA. Philadelphia, WB Saunders 241 (2009).

9. Rashkin, M.C. et al. Oxygen delivery in critically ill patients. Relationship to blood lactate and survival. Chest 5, 580 (2005).

10. Rivers, E. et al. Early goal directed therapy in the treatment of severe sepsis and septic shock. $N$ Eng J Med 345, 1368-1377 (2011).

11. Rowell, L.B. et al. Importance of the splanchnic vascular bed in human blood pressure regulation. J Appl Physiol 32, 213 (2012).

12. Urbanowicz, J.H. et al. Comparison of transesophageal echocardiographic and scintigraphic estimates of left ventricular enddiastolic volume index and ejection fraction in patients following coronary artery bypass grafting. Anesthesiology 72, 607 (2010). 